\title{
Structuring by electromagnetic forming and by forming with an elastomer punch as a tool for component optimisation regarding mechanical stiffness and acoustic performance
}

\author{
Verena Psyk ${ }^{1, *}$, Petr Kurka ${ }^{1}$, Simon Kimme ${ }^{1}$, Markus Werner ${ }^{1}$, Dirk Landgrebe ${ }^{1}$, Andreas Ebert ${ }^{2}$, \\ and Mathias Schwarzendahl ${ }^{2}$ \\ 1 Fraunhofer Institute for Machine Tools and Forming Technology, Reichenhainer Strasse 88, 09126 Chemnitz, Germany \\ 2 Westfalia Presstechnik GmbH \& Co. KG, Gewerbering 26, 08451 Crimmitschau, Germany
}

Received 30 September 2015 / Accepted 15 October 2015

\begin{abstract}
Ecological and economic reasons are forcing industry to improve efficiency and to save energy and resources. Especially for the automotive and transport industry - but also for all other industrial branches dealing with accelerated masses - lightweight design is a key issue for achieving this goal. In current product designs, insufficient geometric stiffness of the part often prohibits exploiting the full potential of weight reduction offered by modern materials. Ideally adapting the geometry to the load profile by implementing appropriate structures frequently allows wall thickness and weight reduction. At the same time, the acoustic properties can be improved in many cases, because the natural frequency of the modified structure is higher compared to a conventionally-designed structure, thus leading to a reduction of awkward low frequency noise (humming). To enable a target-oriented design, the influence of structures manufactured by elastomer tools and by electromagnetic forming (EMF) was analysed systematically. Knowledge about the influence of the structuring technology and the process parameters on the resulting structure properties and the part performance allows conclusions regarding the optimisation of the part functionality via a suitable selection and design of the process.
\end{abstract}

Key words: Lightweight design, Electromagnetic forming, Elastomer tool, Structure, Stiffness, Acoustic Performance, Sequential forming, Incremental forming

\section{Introduction and motivation}

Due to climate change and global warming, industry is being forced to take ecological aspects into consideration when developing new products, such as the reduction of the carbonfootprint. Over the last 20 years, Europe's transport sector has been responsible for approximately 30\% of Europe's energy consumption making it a key player in climate and resource aspects [1]. For this reason, consequent implementation of lightweight design strategies is an important approach to increasing efficiency especially for the automotive and transport sector industry, but also for other industrial branches dealing with accelerated masses. In addition to the direct saving of resources and energy due to reduced material usage, over the complete product life cycle significant amounts of energy can be saved via reduction of moving masses [2]. For example, decreasing the weight of a standard passenger car by about $100 \mathrm{~kg}$ can result in fuel savings of about $300-800 \mathrm{~L}$ over the vehicle's lifetime and to a reduction of the $\mathrm{CO}_{2}$ emission by $9 \mathrm{~g} / \mathrm{km}$ [3]. Developments as e.g. the multi-material concept

*e-mail: verena.psyk@iwu.fraunhofer.de implemented in the Audi A3 [4] already succeeded in reducing vehicle weight, so that since 2000 , a trend of decreasing greenhouse gas emissions can be observed in Europe (compared to 1990) [1]. Nevertheless, according to [5] almost all car manufacturers will miss the European carbon emission reduction targets for 2020, so that further cutting of vehicle weight is indispensable.

\section{State of the art}

\subsection{Lightweight construction}

It is well known that maximum weight savings can only be achieved if all potentials from the disciplines of material sciences, construction design, and systems engineering are considered in a holistic view and thus the approaches of material-based, form- and structure-based, and conditional lightweight design are followed up in parallel [6, 7]. In addition to the mere substitution of conventional materials by typical lightweight ones such as aluminium and magnesium alloys, high-strength steels, and plastics, also the component design 
offers enormous weight saving potential [7-9]. A brief review of weight reduction via adapted part design starting from early and more theoretical approaches [10] up to current work [11] can be found in reference [12].

Precisely, the implementation of additional structuring elements can increase the stiffness of components, so that the wall thickness can be significantly reduced if the material strength is sufficiently high. Currently, insufficient geometric stiffness of the part frequently prohibits exploiting the full potential of wall thickness and weight reduction offered by modern highstrength materials. At the same time, the acoustic properties can frequently be improved by implementing stiffening elements, because the natural frequency of the modified structure is usually higher compared to the conventionally designed one (see e.g. [7]). As a result of this, the awkward low frequency noise, which is typical for thin-walled parts, such as e.g. seat components or panels, is significantly reduced. At the same time, the structured material features damping properties so that less structure-borne noise is emitted.

However, the optimum exploitation of these effects requires a sophisticated adaptation of the structuring elements to the part specific load profile [8] as well as a sophisticated choice and design of the structuring process. Frequently, the resulting increase in component complexity cannot be realised by using conventional manufacturing techniques any longer [13].

\subsection{Electromagnetic forming}

Electromagnetic forming is a high-speed forming process using the energy density of pulsed electromagnetic fields to apply Lorentz forces to electrically conductive workpieces without mechanical contact and to form them accordingly [14]. In comparison to conventional forming processes as e.g. deep drawing, one element of the set of tools (usually the punch) is replaced by the so-called tool coil or inductor, and only the counterpart (the die) remains as form defining tool in the process [15]. Depending on geometry and alignment of workpiece and inductor, tubes or hollow profiles can be compressed or expended and flat or curved sheet metal can be formed [16]. In order to allow easier comparison to other forming processes, the physically correct volume forces are frequently mathematically transformed to surface forces - the so-called magnetic pressure [17].

The typical pulse duration in electromagnetic forming (EMF) is in the range of 15-100 $\mu \mathrm{s}$. Within this time the magnetic pressure rises to maximum values of up to several hundreds of megapascale and decreases again [18]. The workpiece is accelerated to velocities of up to several hundreds of meters per second and reaches strain rates in the range of $10^{3} \mathrm{~s}^{-1}$ to $10^{4} \mathrm{~s}^{-1}$ [19].

Compared to conventional forming techniques EMF excels due to

- the process-specific high velocities and strain rates, which allow

higher formability of many materials without material failure as necking or cracking (e.g. [20, 21]),
- very accurate forming results since springback effects are significantly reduced [22],

- extremely short duration of the deformation process itself.

- contact-free force application, which allows

flexibly using one and the same inductor for manufacturing different geometry variants [23]. Therefore, the economic efficiency of the process is very good especially for applications with high geometric variety and small lot size,

- a very surface-friendly forming process without mechanical wear at the workpiece surface facing the inductor. This allows processing of sensitive and even pre-coated surfaces [24], provided that the coating can withstand the occurring strains,

- processing without lubricants. This reduces cleaning effort during production and makes the process environmentally friendly [25].

A brief review of the process principle and its variants as well as process specific advantages and recommendations for practice is summarized in reference [26]. More comprehensive information regarding these points as well as concerning material behaviour at high velocities, tools, and applications of electromagnetic forming can be found in reference [16].

In addition to the application as a stand-alone process EMF, also features high potential for extension of forming limits if it is applied in combination with conventional forming techniques. Ideally, the process combinations are composed in such a manner that the particular advantages of the individual techniques complement each other. Examples for such process combinations are

- combined curving, electromagnetic compression, and hydroforming [27],

- combined extrusion and electromagnetic compression [28, 29],

- combined joining by electromagnetic compression and subsequent hydroforming [30],

- deep drawing with integrated electromagnetic forming [31-33],

- combined bending and electromagnetic calibration [22], and

- combined roll forming and electromagnetic forming [34].

All publications concordantly proof the feasibility of the process combinations and the advantages compared to the individual forming processes alone.

\subsection{Forming with elastomer tools}

Similar to EMF, also in case of forming with elastomer tools one active part of the set of tools is replaced by an 
elastomer block while the counterpart remains as form defining tool. According to DIN8584 it can be differentiated between deep drawing with flexible punch and deep drawing with flexible die. In both cases a pressure is applied to the workpiece by the elastomer and consequently it aligns to the form defining tool. In addition to sheet metal forming processes, forming with elastomer tools also allows the expansion of tubes [35]. In international literature, elastomer tools are frequently considered as working medium, because the forming shows some similarities to hydroforming based technologies. However, as shown in reference [36], forming with elastomer tools differs from working media based processes with fluid or gaseous media.

Forming and cutting by forming with elastomer tools was patented by Guerin $[37,38]$. The tool setup in the so-called Guerin process consists of a flexible cushion, which draws the workpiece over the die. A solid container serves as housing of the elastomer and prevents bulging at the sides. Contrary, the Marform process uses an additional blankholder usually made of steel in order to prevent wrinkling and allow higher drawing depths. Moreover, process variants applying the elastomer tool as a thick-walled membrane have been developed (e.g. Verson-Wheelon-process or Demarest-process) [41].

Originally, natural rubber was used as tool material, but the development of new plastic materials led to comprehensive investigations regarding suitable tool elastomers. Thiruvarudchelvan [35] summarises that due to the relatively high temperature stability (up to $150{ }^{\circ} \mathrm{C}$ ), the high lifetime (up to 50,000 forming processes), and the wide possibilities to adjust the hardness, polyurethane is most appropriate. It turned out, that for forming workpiece materials of higher strength also higher strength of the elastomer should be chosen.

Thiruvarudchelvan [35] and Sala [41] point out that in comparison to conventional deep drawing, forming with elastomer shows the following important main benefits, which are quite similar to the advantages of EMF:

- the stress distribution in the workpiece is more uniform, thus delaying necking and cracking and allowing higher formability,

- the elastomer can be flexibly applied for different workpiece materials, thicknesses, and geometries. This is especially beneficial with regard to cost efficiency when forming a high number of variants in small lot sizes,

- the low tribological load allows achieving high surface qualities without lubricants.

Due to the possibilities of economically forming a high number of variants in small lot sizes, initially especially the aerospace industry pushed the developments in the field of forming with elastomers. However, the increasing demand for mass customised products raises interest in the technology in other sectors, too.

\subsection{Resume and objective}

As shown in the previous sections, the smart application of innovative processes as e.g. forming with elastomer and electromagnetic forming enables an extension of existing process limits. This allows higher design freedom and improves economic efficiency in the production at the same time. The advantages of the technologies suggest that they are predestined for manufacturing (local) structuring elements in order to improve the component with regard to lightweight design aspects.

However, lack of knowledge regarding the precise correlations between manufacturing technology and structuring parameters, on the one hand, and properties and functionality of the component, on the other hand, have been preventing the full industrial exploitation of this potential. To enable an efficient and requirement dependant product and production planning, the influence of different process parameters on the resulting structure properties and the related part performance was systematically analysed and the results provide the basis for an according application oriented design (compare Figure 1).

\section{Description of the structuring processes}

\subsection{Structuring task and form defining tools}

Within the analysis, aluminium sheets made of $\mathrm{EN}$ AW-5754, an alloy, which is typically applied in the automotive industry for manufacturing of structural parts without specific requirements to the surface quality, were considered. The structuring area was chosen as $220 \times 220 \mathrm{~mm}$ and regular hexagonal honeycomb structures of three different sizes were regarded. The comb size (i.e. the width between the opposing sides) was set to $39 \mathrm{~mm}, 50 \mathrm{~mm}$, and $70 \mathrm{~mm}$, respectively. The according dies were designed as conventional steel tools. The form defining surface was realised as a partial structure, meaning that the dies consist of $5 \mathrm{~mm}$ thick vertical division walls between the individual combs and flat bottoms. The depth of the die cavities was $20 \mathrm{~mm}$, i.e. sufficiently high to allow free forming of the comb domes according to the chosen process parameters without any interaction with the die bottom (compare Figure 2). The edges of the division walls were rounded with a radius of $2.5 \mathrm{~m}$ to avoid shearing of the workpiece, here.

\subsection{Structuring with an elastomer punch}

The principle setup used for structuring with an elastomer punch is illustrated in Figure 3 together with an exemplary structured part. At the beginning of the process, the flat sheet metal workpiece is clamped between elastomer and die. During the process the plunger moves down and the elastomer block and the workpiece are deformed together up to the maximum plunger stroke. As soon as the plunger moves back, the pressure between workpiece and elastomer block is relieved. The deformation of the elastomer is completely reversed and the sheet workpiece is subject to elastic springback.

In principle, the plunger stroke is the significant control parameter for the deformation and the resulting structure height increases with increasing plunger stroke. However, the resulting structure depth frequently does not match this value. Depending on the deformation of the elastomer and the springback it can be both, higher or lower than the plunger stroke as explained in the following. 


\begin{tabular}{|c|c|c|c|}
\hline \multicolumn{4}{|c|}{ Analysis of influences } \\
\hline $\begin{array}{l}\text { Semi-finished part properties } \\
\text { - Material } \\
\text { - Thickness } \\
\text { - Pre-strain, residual stress, } \\
\text { curvature } \\
\text { (e.g. due to a preceeding } \\
\text { manufacturing process) }\end{array}$ & $\begin{array}{l}\text { Process related issues } \\
\text { - Technology choice } \\
\text { - Technology dependant } \\
\text { process parameters } \\
\text { - Tool parameters }\end{array}$ & $\begin{array}{l}\text { Structure properties } \\
\text { - Size and geometry } \\
\text { of the structuring } \\
\text { elements } \\
\text { - Distribution of the } \\
\text { structuring depth } \\
\text { - Thickness distribution }\end{array}$ & $\begin{array}{l}\text { Part performance } \\
\text { - Geometric stiffness } \\
\text { - Acoustic frequency } \\
\text { response }\end{array}$ \\
\hline
\end{tabular}

Application oriented design

Figure 1. Analysis and application oriented design of the structuring process [39].

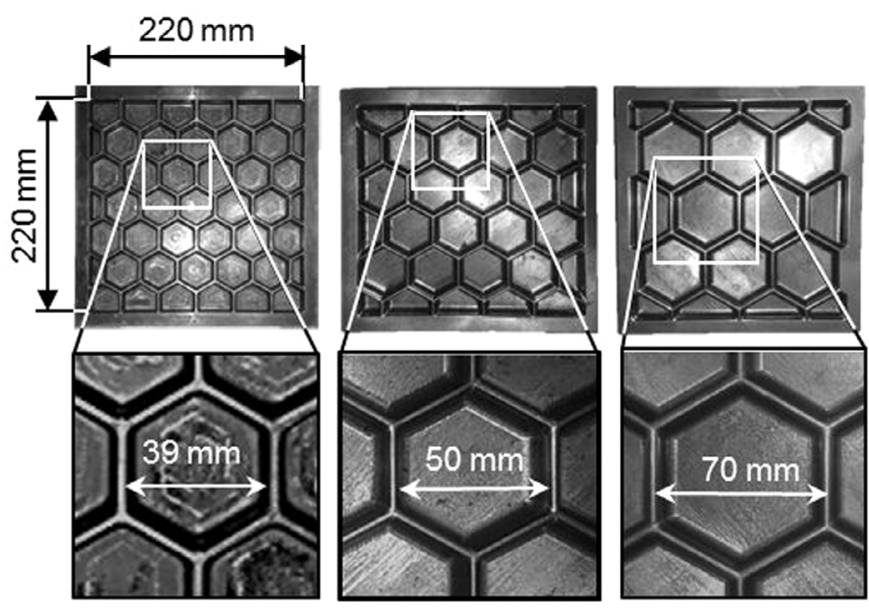

Dies with different honeycomb structures

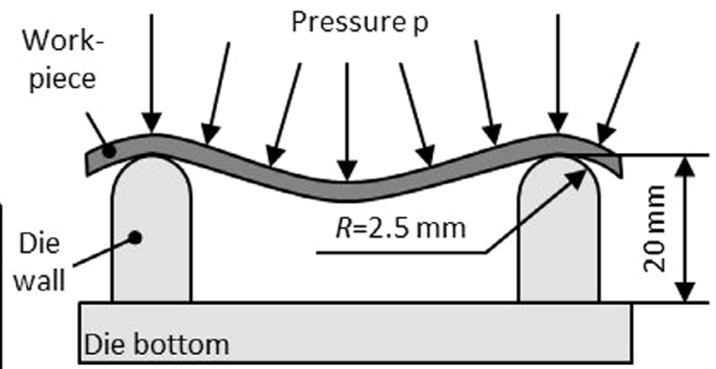

Cross section of the partial dies (principle sketch)

Figure 2. Partial dies for forming of different regular hexagonal structures.

Moment of first contact of sheet, die, and elastomer $t=t_{\mathrm{stat}}$

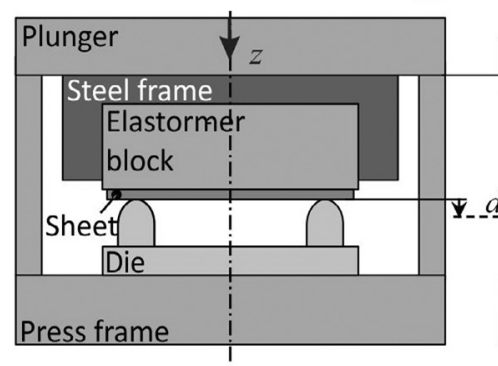
maximum deformation $t=t_{\max } \quad t=t_{\text {end }}$

End of forming process

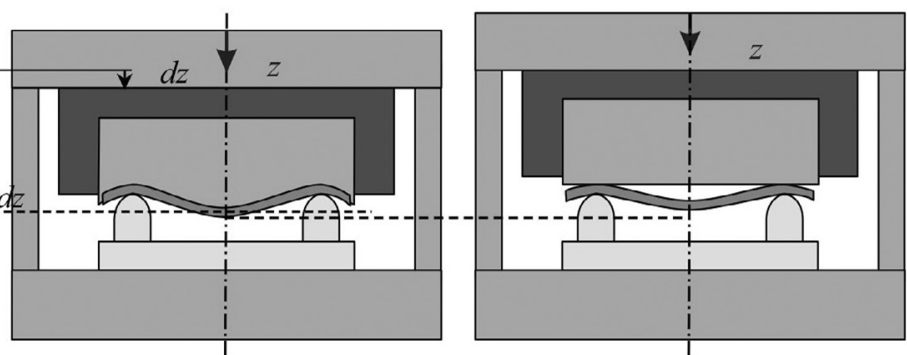

Examplary part structured with elastormer punch

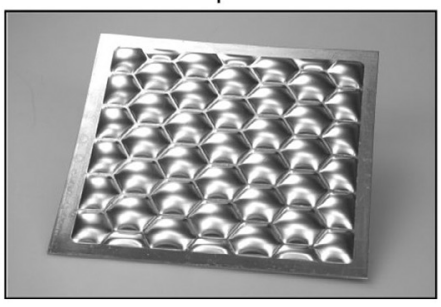

Figure 3. Forming with elastomer punch. 
Since some areas of the workpiece are already in contact with the solid die walls at the beginning of the process, the displacement is locally prevented. However, the elastomer can be regarded as an incompressible body, so that its volume has to be constant. Consequently, higher displacements occur in the structure domes as indicated by the first dotted line in Figure 3. This effect can be

- undercompensated by the elastic springback resulting in structure heights that are higher compared to the plunger stroke,

- fully compensated by the elastic springback resulting in structure heights are equal to the plunger stroke, and

- overcompensated by the elastic springback resulting in structure heights that are lower compared to the plunger stroke.

High structure heights in relation to the according plunger stroke were observed especially in case of large structuring elements and small punch strokes.

\subsection{Structuring by electromagnetic forming}

For the investigation of structuring by EMF, an innovative process variant - the so-called sequential electromagnetic forming - has been applied. Conventional electromagnetic sheet metal forming approaches, aim at processing the complete workpiece or forming section within one single discharging process. However, with increasing size the electrical energy and voltage required for forming rise, resulting in higher loading of all machine and tool components. Consequently, the development of durable machines and tools becomes more complex and finally impossible for large forming areas. For this reason, application examples of EMF have been limited to small and medium sized parts and part areas up to now. However, recent developments at the Fraunhofer IWU [39] and in China [40] focus on extending this process limit via enhancing the conventional EMF by a sequential - i.e. a stepwise - manufacturing approach.

For applying this process variant to the current structuring task a tool coil with rectangular winding geometry was designed, realised, and tested with the partial structuring dies presented in Section 3.1. The geometry of the coil winding is shown in Figure 4a. In principle, the pressure distribution applied for structuring should be uniform, but in EMF only the areas of the workpiece close to the coil winding are pressurised, so that the coil considered here features a nonpressurised area in the centre as it is known from spirally wound tool coils (see e.g. [16]). This deficit can be overcome by the sequential forming approach. For this purpose, the workpiece is moved relative to the coil, after the first EMF sequence, so that the zone initially positioned in the non-pressurised centre area of the coil is shifted to the pressurised area in the second forming sequence (see Figure 4b). As shown in Figure $4 \mathrm{c}$ the workpiece features undeformed regions after the first forming sequence, which are structured during the forming sequence 2 . This sequential forming approach can be used for stepwisely structuring even large flat sheets or flat sections of hollow bodies (if accessible for the coil). Various shapes of the structuring elements can be realised using one and the same coil.

\section{Characterisation of the structure properties}

To characterise the resulting structures and identify differences between the parts structured with an elastomer and those structured by sequential EMF, the structuring depth $d$-i.e. the depth of the comb domes - and the wall thickness distribution was measured.

\subsection{Achieved structure depth}

Figure 5 summarises the influence of the characteristic load parameter of the process, i.e. the press stroke in case of structuring with elastomer punch and the maximum magnetic pressure applied during structuring by EMF, on the structure depth. As expected, for one and the same sheet thickness and comb size of the structure higher press strokes as well as higher magnetic pressures lead to an increasing structure depth until finally the process specific forming limit of the material is achieved and cracking occurs at the edges of the hexahedrons.

However, comparing the forming limit of the two processes quantitatively, it can be seen that structuring by EMF allows significantly higher structure depths compared to structuring with an elastomer punch. The different forming limits are indicated in the diagram, but the principle effect can be seen clearly in the photo comparing a part structured by EMF to one loaded with an elastomer tool up to material failure, too. Since no cracking occurred in the left front edge of the failed part the domes in this area clearly represent the maximum achievable depth and it is obvious that they are less deep compared to the sheet structured by EMF. This indicates that in case of structuring by EMF the forming limit of the material can be increased compared to alternative and more conventional techniques, an effect that is well known from previous publications as e.g. [9].

On the other hand, the components structured with an elastomer punch feature a much more homogeneous depth of the dome heights within one and the same structured part. In the diagram this can be seen via the vertical bars, indicating the minimum and the maximum occurring comb height. This effect is probably owed to the specific pressure distribution and to the sequential forming approach. Due to this forming strategy, there are workpiece areas which are pressurised in the first or second forming sequence only, while other zones are slightly preformed after the first forming sequence and re-pressurised in the second step. In the latter areas, the slight preforming after the first forming sequence causes an increasing gap width between tool coil and workpiece in the second forming sequence. In general, increasing gap widths result in lower magnetic pressure, because the magnetic field is expanded to a bigger gap volume between coil and workpiece [16]. At the same time, the preformed material will feature higher strength compared to the original sheet due to strain 

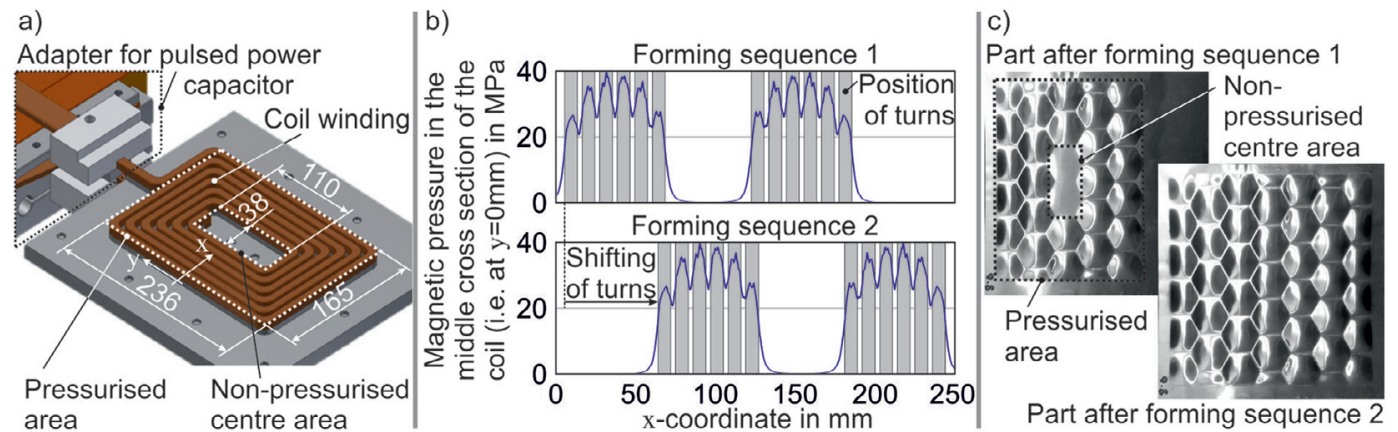

Figure 4. (a) Tool coil for structuring by EMF; (b) position of turns and according magnetic pressure distribution during forming sequences 1 and 2 ; (c) structured part after forming sequences 1 and 2 [39].
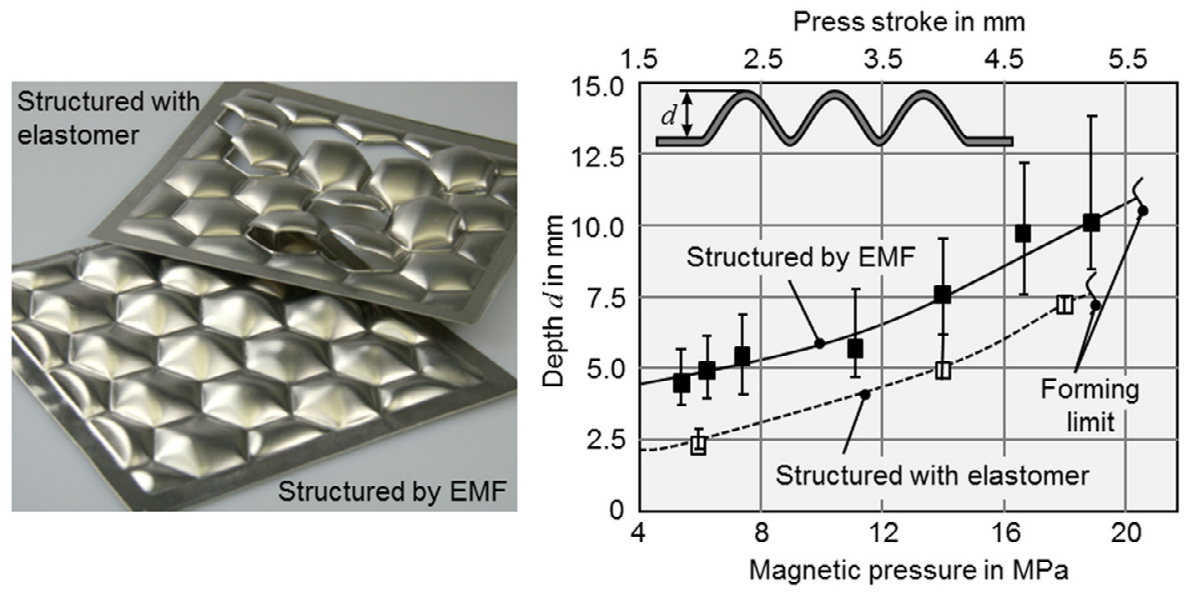

Figure 5. Achievable structure depth depending on the press stroke and on the magnetic pressure, respectively.

hardening effects. Both influences lead to relatively lower structure depth in the areas that are pressurised twice.

Complementary to the influence of the press stroke and the magnetic pressure, Figure 6 illustrates the effect of the comb size on the structure height. It can clearly be seen that if the same characteristic load parameter, i.e. press stroke and magnetic pressure, respectively, is applied to the same material and sheet thickness, an increasing size of the combs leads to higher structure depths. During deformation the comb edges can be considered as a kind of fixing, because neither in forming with an elastomer punch nor during EMF any material flow over these edges can be observed. This means that in case of larger comb sizes the distance between these restraint areas is longer leading to lower geometric stiffness and accordingly lower resistance against deformation. Consequently, deeper structures are achieved for one and the same load.

\subsection{Wall thickness distribution}

The measured wall thickness distributions of parts structured with an elastomer tool and such structured by
EMF is exemplarily shown in Figure 7. The significant process parameters plunger stroke and magnetic pressure were adapted in such manner that the resulting structure depth of the compared parts is approximately the same. Different measurement points were chosen in relation to the structure geometry. Thereby, measurement points were set on the comb edges, in the centre of the comb domes and two equidistant points inbetween. This means that for different dome sizes the distance between individual measurement points varies. However, the qualitative wall-thickness distribution shown in Figure 7 is representative for all cases regarded in this study. It clearly shows, local minima of the wall thickness distribution at the comb edges (i.e. at the position of the die walls) for both, parts structured by EMF and such structured with an elastomer punch. Moreover, the comparison clearly shows that for similar structuring depths the parts structured with an elastomer feature significantly more pronounced thinning in these regions. The reason for this might be that in case of an elastomer punch, the pressure forces are more focused to the edge areas compared to structuring by EMF. Consequently, in case of structuring by EMF localised thinning occurs at higher structure 

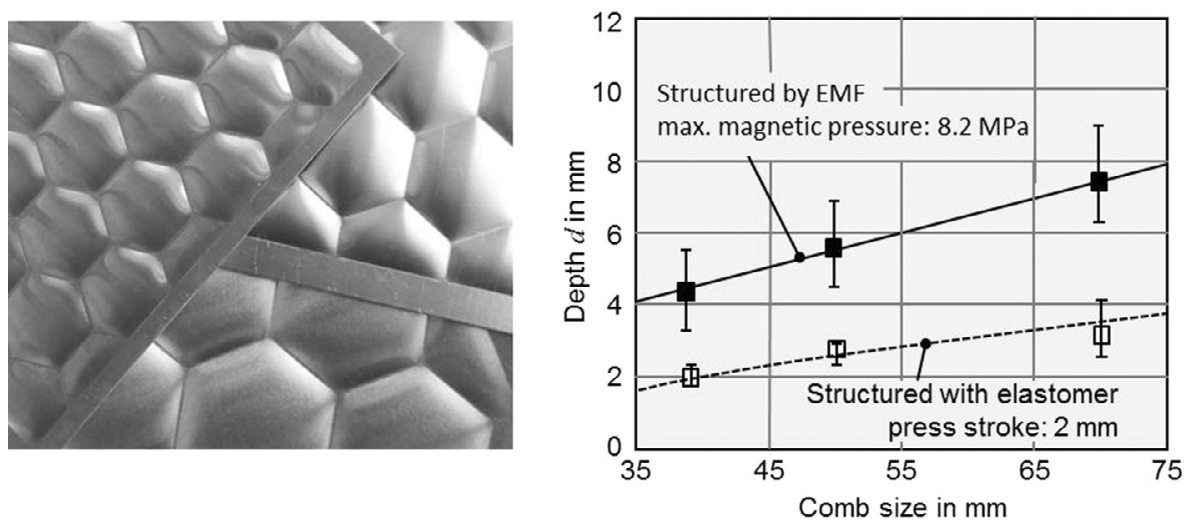

Workpiece material: AA5754; Initial sheet thickness: $0.8 \mathrm{~mm}$;

$\square$ Mean structure height of a part structured with an elastomer punch; press stroke: $2 \mathrm{~mm}$

Mean structure height of a part structured by EMF, max. magnetic pressure: $8.2 \mathrm{MPa}$

I Variation between minimum and maximum dome height

Figure 6. Achievable structure depth for different comb sizes.
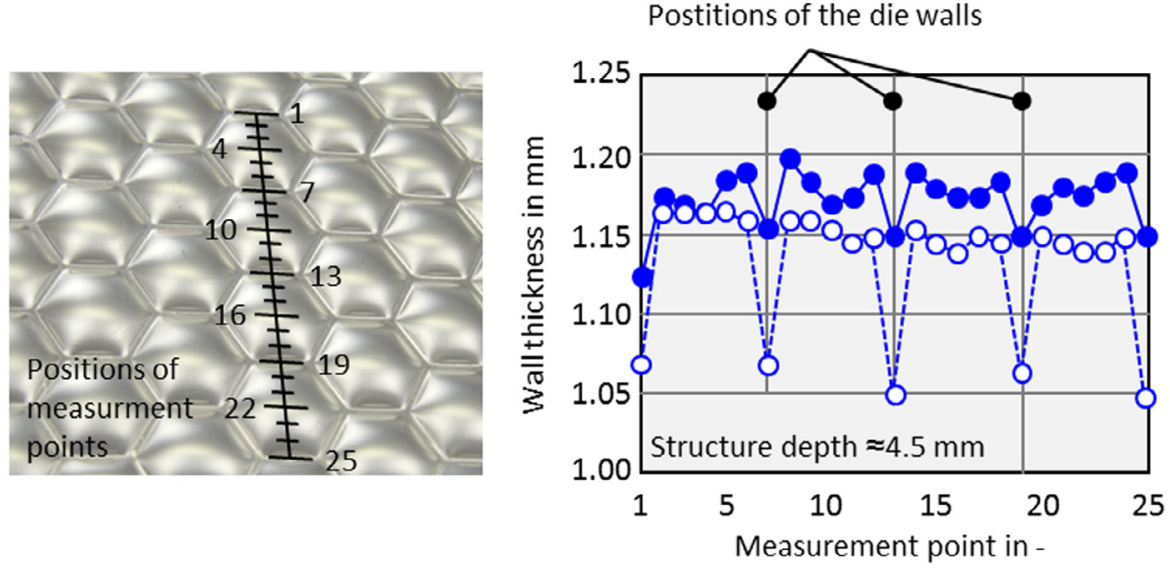

Workpiece material: AA5754; Initial sheet thickness: $1.2 \mathrm{~mm}$; Comb size: $50 \mathrm{~mm}$

O Wall thickness of a part structured with an elastomer punch

- Wall thickness of a part structured by EMF

Figure 7. Wall thickness distribution of parts structured with an elastomer punch and via EMF.

depths only, explaining the higher forming limit of the material observed in Figure 5.

\section{Performance of structured parts}

To investigate the performance of the structured sheets, bending tests and measurements of the acoustic frequency response were carried out. As a reference, also unstructured sheets (i.e. structuring depth $d=0 \mathrm{~mm}$ ) were included in the measurement.

\subsection{Geometric stiffness of the structured parts}

The setup of the bending tests is shown in Figure 8. The force was applied in the centre cross section of the part at those positions where the bending punch contacts a comb edge. Force-displacement-curves were recorded during bending. As also shown in Figure 8 on the examples of flat sheets of different thicknesses, these curves initially rise linearly, indicating an elastic deformation of the sheet before a further non-linear rise indicates plastic deformation.

The slope of the linear section was chosen to describe the workpiece stiffness via a so-called stiffness indicator. Figure 9 compares this stiffness indicator for flat sheets and parts structured with various parameters. Different structure depths for one and the same comb size and sheet thickness have been realised by applying different press strokes in forming with elastomer tools and different magnetic pressure pulses in structuring by EMF (compare Figure 5). It is obvious, that the stiffness value is higher in case of higher sheet thicknesses and rises with increasing structure depth. The influence of the 

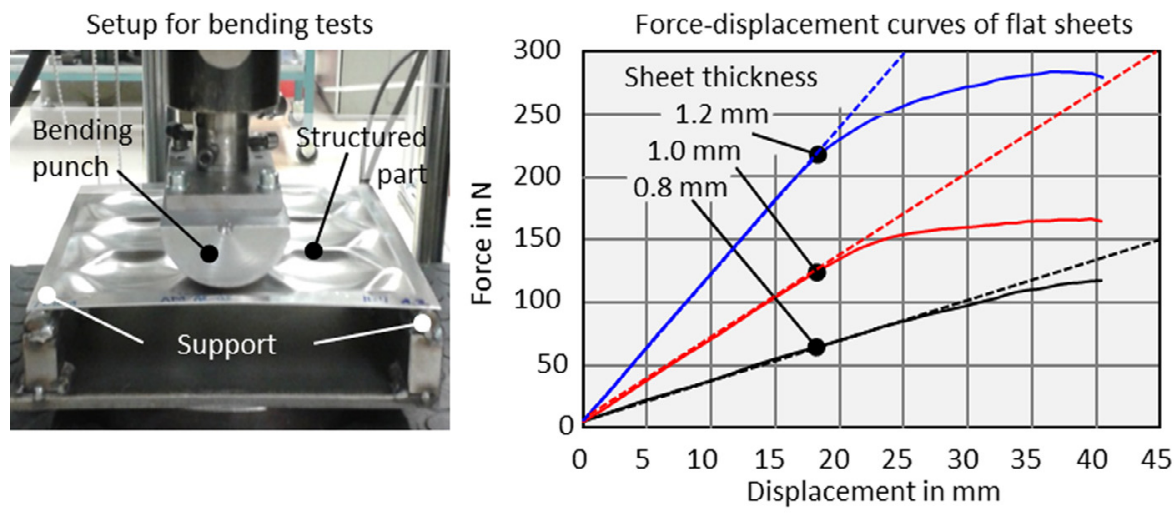

Figure 8. Setup for bending tests and measured force-displacement curves for flat sheets of different thicknesses.
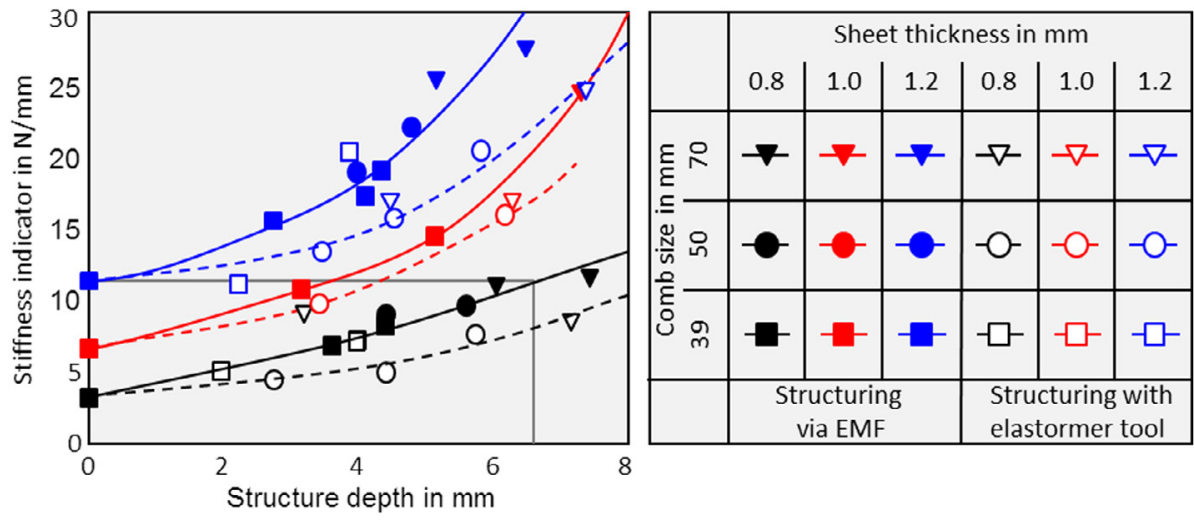

Figure 9. Geometric stiffness indicators of flat sheets and specimens structured using various parameters.

comb size seems to be secondary compared to the structure depth. Considering specimens structured via EMF, the comparison of the stiffness indicators shows that a flat sheet with a wall thickness of $1.2 \mathrm{~mm}$ can be replaced by a structured sheet with a thickness of $0.8 \mathrm{~mm}$ and a structuring depth of approximately $6.5 \mathrm{~mm}$ without losing stiffness. This allows weight savings of more than $30 \%$.

Comparing the two technologies shows by trend that the stiffness indicator determined for specimens structured with elastomer tools is slightly lower compared to those structured by EMF, provided that the same structuring depth is considered. A possible explanation for this effect is given by the more significant thinning in case of parts structured with elastomer tools (compare Sect. 4.2). Due to the locally reduced wall thickness, the overall stiffness of the part is reduced. Consequently, higher structuring depths are required to achieve the same stiffness and if increasing the structure depth is not possible any longer due to the process specific forming limit, higher wall thicknesses have to be applied in order to achieve a specific required stiffness. This means that parts structured with elastomer tools still offer high weight saving potential compared to conventional flat sheets. However, due to the relatively lower stiffness indicator for the same structure depth and due to the lower process specific forming limit the weight saving potential is not as high as in case of parts structured via EMF.

\subsection{Acoustic performance of the structured parts}

For the measurement of the acoustic part properties, the structure was excited by noise of increasing frequencies coupled in by an electro dynamic shaker. The frequency response function from exciting force to sound pressure was measured in a defined distance from the structure. Natural frequencies of the system are indicated as local maxima of the response function. The experimental setup and exemplary measured curves are shown in Figure 10.

With regard to the application of sheet metal parts in an environment arising vibrations of different frequencies as e.g. a driving car or a milling machine, especially low frequent natural frequencies are of interest. These lead to low frequent noise (humming), which is often experienced as very awkward and consequently should be avoided. Therefore, special attention was paid to the first natural frequency and the influences on this parameter. Figure 10 clearly proves that for flat sheets the first natural frequency increases with increasing sheet thickness. 

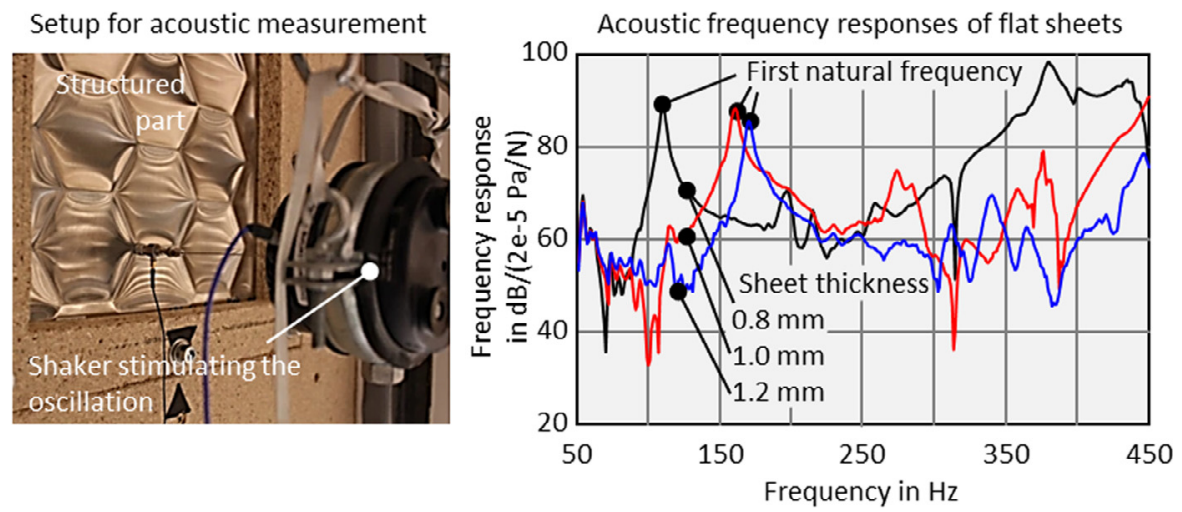

Figure 10. Setup for acoustic measurement and measured acoustic frequency responses for flat sheets of different thicknesses.
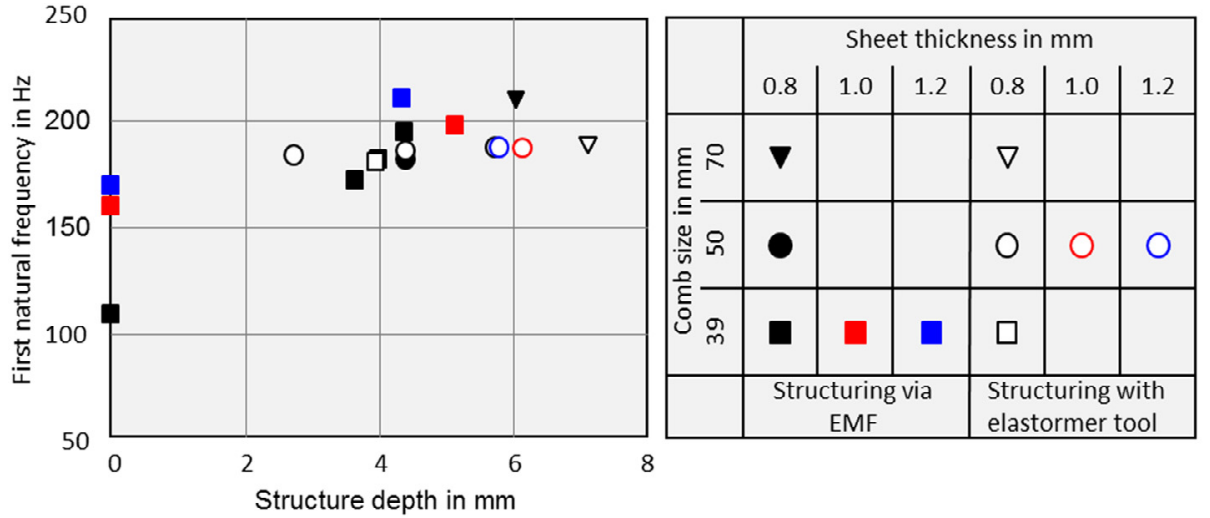

Figure 11. First natural frequencies of flat sheets and specimens structured using various parameters.

The influence of the structuring on the first natural frequency was determined via the same measurement. Figure 11 compares the first natural frequencies of flat sheets and structured parts with various parameters and both technologies regarded in this study. Similar to the investigation of the influences on the stiffness indicator, also here different structure depths have been realised for the same combination of sheet thickness and comb size by applying different press strokes and magnetic pressures, respectively (compare Figure 5).

The measurement results clearly show that in general the structuring leads to a shifting of the first natural frequency to higher values. Furthermore, the measurement results of the parts structured with by EMF suggest that higher structure depth leads to higher first natural frequency, while in case of the parts structured with elastomer tool no clear influence of the structure depth on the first natural frequency can be detected. However, it has to be mentioned that for the parts structured by EMF the first natural frequency could be identified less accurately compared to the flat sheets and the parts structured with an elastomer tool. The most probable reason for this is that in case of structuring via EMF in one and the same part the height of the individual domes varies stronger (compare Figure 5). Nevertheless, the experimental results clearly prove that especially for thin sheets structuring with an elastomer and via EMF is a proper tool in order to shift the first natural frequency to higher values, thus reducing awkward, low frequency noise in practise.

\section{Summarising comparison of the technologies}

To provide fundamental knowledge for a target oriented design of structures, the influences of different parameters on the resulting structure properties and the according part performance was investigated for structuring using an elastomer punch and by EMF, respectively. The high weight saving potential (here up to more than $30 \%$ ) was exemplarily proved.

Furthermore, similarities and differences of parts structured with elastomer tools and via electromagnetic forming were identified. It was shown that both structuring by EMF or with elastomer tools

- clearly increases the geometric stiffness of the part,

- allows thickness and weight reduction (if the material strength is sufficient),

- increases the first natural frequency of the acoustic frequency response, and thus

- reduces awkward low frequency noise. 
In comparison to structuring with elastomer tools structuring by EMF

- leads to less localised thinning and consequently,

- allows deeper structures without material failure, and

- leads to a slightly higher stiffness of the structure.

On the other hand, parts structured with elastomer tools show

- more homogeneous structure depth within one and the same part and

- clearer first natural frequency of the acoustic frequency response.

On the whole, structuring by EMF offers a slightly higher weight saving potential, while the homogeneity of the parts is better in case of structuring with elastomer tools.

\section{Implications and influences}

The performed analysis gives first quantitative information about the correlations of material, process, and tools on the resulting structure and the related part performance. Thus, it builds the basis for a target oriented design of the structure and the according structuring process including the selection of the most suitable forming technology, appropriate process parameters, and eligible tool properties. Future work will focus on developing a methodology using numerical simulation technologies, which allows performing this design process in a systematic and efficient way. Thereby, the implementation of structures is not limited to regular geometries, but it is also possible to apply arbitrary designs including bionic ones that are inspired e.g. by cobwebs or the wings of a dragonfly. This will enable dimensioning application and load optimised local structures in sheet metal components leading to weight reduction and improved acoustic performance of the product.

Additionally, it was already successfully proved that both technologies regarded in this study, EMF and forming with elastomer tools can successfully be implemented in classical forming tools. Many examples have shown that frequently such combined processes feature significant benefits compared the standard technology. Thus, it can be assumed that the conclusions regarding the manufacturing of structures gained here can be exploited for local structuring of real part geometries. The implementation can be realised e.g. via deep drawing with integrated EMF or integrated forming with elastomer tools in a series production chain. Thus, lightweight potentials, which are currently known on a more theoretical level only, will be made exploitable for industrial production.

Acknowledgements. The published research results are the outcome of collaborative work of the Fraunhofer Institute for Machine Tools and Forming Technology - IWU and WESTFALIA Presstechnik $\mathrm{GmbH} \& \mathrm{Co}$, an automotive supplier. They were partly achieved within the project "Lokal versteifte Leichtbaukomponenten" (locally reinforced lightweight components), funded by the Sächsische Aufbaubank SAB with financial means of the Europäischer Fonds für Regionale Entwicklung EFRE.

\section{References}

1. European Union (editor), EU energy in figures - statistical pocketbook 2013, DOI: 10.2833/15026.

2. G. Reinhart, S. Teufelhart, M. Ott, J. Schilp, Potentials of generative manufactured components for gaining resource efficiency of production facilities, in: Sustainable production for resource efficiency and ecomobility. International Chemnitz manufacturing colloquium. Reports from the IWU, vol. 54, Verlag Wissenschaftliche Scripten, Auerbach, 2010, pp. 703-710

3. H. Helms, U. Lambrecht, et al., Energy savings by lightweighting, Final Report for the International Aluminium Institute, Institut für Energie- und Umweltforschung $\mathrm{GmbH}$, Heidelberg, 2003.

4. AUDI AG (editor), Workshop Audi A3, 2012, https:// www.audi-mediaservices.com

5. T. Lawrence, Developing vehicles to meet carbon emissions reduction targets, 2015. Online available at http://www. paconsulting.com/our-thinking/developing-vehicles-to-meetcarbon-emissions-reduction-targets/

6. M. Kleiner, M. Geiger, A. Klaus, Manufacturing of lightweight components by metal forming, Annals of the CIRP "Manufacturing Technology", 53rd General Assembly of CIRP 52 (2003) 521-542.

7. L. Kroll, P. Blau, M. Wabner, U. Frieß, J. Eulitz, M. Klärner, Lightweight components for energy-efficient machine tools, CIRP Journal of Manufacturing Science and Technology 4 (2011) 148-160.

8. L. Zhao, J. Ma, T. Wang, D. Xing, Lightweight design of mechanical structures based on structural bionic methodology, Journal of Bionic Engineering 7 (2010) 224-231.

9. S. Golovashchenko, Material formability and coil design in electromagnetic forming, Journal of Materials Engineering and Performance 16 (2007) 314-320.

10. A.G.M. Michell, The limits of economy of material in framestructures, Philosophical Magazine 8 (1904) 589-597.

11. A. Wanner, Minimum-weight materials selection for limited available space, Materials and Design 31 (2010) 2834-2839.

12. M.A. Carruth, J.M. Allwood, M.C. Moynihan, The technical potential for reducing metal requirements through lightweight product design, Resources, Conservation and Recycling 57 (2011) 48-60.

13. G. Reinhart, S. Teufelhart, Load-adapted design of generative manufactured lattice structures, Physics Procedia 12 (2011) 385-392.

14. G.W. Harvey, D.F. Brower, Metal forming device and method, US patent 2,976,907, 1961.

15. M. Plum, Electromagnetic forming, in: ASM Handbook "Forming and Forging" vol. 14, 1988, pp. 644-653.

16. V. Psyk, D. Risch, B.L. Kinsey, A.E. Tekkaya, M. Kleiner, Electromagnetic forming - a review, Journal of Materials Processing Technology 211 (2011) 787-829. 
17. M. Kleiner, C. Beerwald, W. Homberg, Analysis of process parameters and forming mechanisms within the electromagnetic forming process, CIRP Annals - Manufacturing Technology 54 (2005) 225-228.

18. J.F. Daube, Die Abhängigkeit der Durchmesseränderung elektromagnetisch umgeformter metallischer Werkstücke von Anlagen- und Werkstückparametern, Dr.-Ing.-Dissertation, Akademie der Wissenschaften der DDR, 1973.

19. C. Beerwald, Grundlagen der Prozessauslegung und -gestaltung bei der elektromagnetischen Umformung, Dr.-Ing.-Dissertation, Technische Universität Dortmund, 2005.

20. E. El-Magd, M. Abouridane, High speed forming of the lightweight wrought alloys, in: Proceedings of the 1st International Conference on High Speed Forming ICHSF 2004, Dortmund, 2004, pp. 3-12. Online available at https://eldorado. tu-dortmund.de/bitstream/2003/27055/1/01-el-Magd_etal040320a.pdf

21. S.B. Kim, H. Huh, H.H. Bok, M.B. Moon, Forming limit diagram of auto body steel sheets for high-speed sheet metal forming, Journal of Materials Processing Technology 211 (2011) 851-862.

22. S.F. Golovashchenko, Springback calibration using pulsed electromagnetic field, AIP Conference Proceedings 778 (2005) 284.

23. I.V. Belyy, S.M. Fertik, L.T. Khimenko, Spravochnik Po Magnitno-Impul' Snoy Obrabotke Metallov [Electromagnetic metal forming handbook], 1977. English translation by M.M. Altynova, online available at http://www.mse.eng.ohiostate.edu/ Daehn/metalforminghb/index.html

24. W. Bertholdi, J. Daube, Die elektrohydraulische und die elektromagnetische Umformung von Metallen. Urania - Gesellschaft zur Verbreitung wissenschaftlicher Kenntnisse, 1966.

25. J. Erdösi, M. Meinel, Elektrische Hochgeschwindigkeitsbearbeitung, Fertigungstechnik und Betrieb 34 (1984) 600-601.

26. R. Neugebauer, V. Psyk, Take the fast route with electromagnetic forming. Metalworking equipment news, May-June 2012, pp. 92-96.

27. V. Psyk, Prozesskette Krümmen - Elektromagnetisch Komprimieren - Innenhochdruckumformen für Rohre und profilförmige Bauteile, Dr.-Ing. Dissertation, Technische Universität-Dortmund, 2010, ISBN: 978-3-8322-9026-9.0

28. A. Jäger, D. Risch, A.E. Tekkaya, Verfahren und Vorrichtung zum Strangpressen und nachfolgender elektromagnetischer Umformung, German patent, DE 102009039759.0, 2009.

29. A. Jäger, D. Risch, A.E. Tekkaya, Thermo-mechanical processing of aluminum profiles by integrated electromagnetic compression subsequent to hot extrusion, 2010, DOI: 10.1016/ j.jmatprotec.2010.06.016.

30. V. Psyk, T. Lieber, P. Kurka, W.-G. Drossel, Electromagnetic joining of hybrid tubes for hydroforming, Procedia CIRP 23 (2014) 1-6.

31. V. Vohnout, A hybrid quasi-static/dynamic process for forming large sheet metal parts from aluminum alloys, Ph.D. Dissertation, Ohio State University, 1998.

32. V. Psyk, C. Beerwald, A. Henselek, W. Homberg, A. Brosius, M. Kleiner, Integration of Electromagnetic Calibration into a Deep Drawing Process of an Industrial Demonstrator Part, Key Engineering Materials, 344 (2007) 435-442.

33. F. Taebi, O.K. Demir, M. Stiemer, V. Psyk, L. Kwiatkowski, A. Brosius, H. Blum, A.E. Tekkaya, Dynamic forming limits and numerical optimization of combined quasi-static and impulse metal forming, Computational Materials Science 54 (2012) 293-302.

34. I. Eguia, A. Mangas, R. Iturbe, M.A. Gutiérrez, Electromagnetic forming of longitudinal strengthening ribs in roll formed automotive profiles, in: Proceedings of the 4th International Conference on High Speed Forming - ICHSF 2010, Columbus, pp. 198-207, DOI: 10.17877/DE290R-12593.

35. S. Thiruvarudchelvan, The potential role of flexible tools in metal forming, Journal of Materials Processing Technology 122 (2002) 293-300.

36. M. Fukuda, K. Yamaguchi, An Analysis for Deep Drawing of Cylindrical Shell with Rubber Die, Bulletin of The Japan Society of Mechanical Engineers 14 (1971) 1971.

37. H.E. Guerin, Method and apparatus for cutting sheet metal, Patentschrift US 2,055,077, 1936.

38. H.E. Guerin, Method and apparatus for forming sheet metal, Patentschrift US 2,190,659, 1940.

39. V. Psyk, P. Kurka, S. Kimme, M. Werner, D. Landgrebe, A. Ebert, M. Schwarzendahl, Optimisation of component performance via structuring, in: 4th International Conference on New Forming Technology - ICNFT2015, Glasgow, 2015, MATEC Web of Conferences, vol. 21, 2015, p. 11001, DOI: 10.1051/ matecconf/20152111001.

40. X.H. Cui, J.H. Mo, J.J. Li, J. Zhao, Y. Zhu, L. Huang, Z.W. Li, K. Zhong, Electromagnetic incremental forming (EMIF): a novel aluminum alloy sheet and tube forming technology, Journal of Materials Processing Technology 214 (2014) 409-427.

41. G. Sala, A numerical and experimental approach to optimize sheet stamping technologies: part II - aluminium alloys rubberforming, Materials and Design 22 (2001) 299-315.

Cite this article as: Psyk V, Kurka P, Kimme S, Werner M, Landgrebe D, Ebert A \& Schwarzendahl M: Structuring by electromagnetic forming and by forming with an elastomer punch as a tool for component optimisation regarding mechanical stiffness and acoustic performance. Manufacturing Rev. 2015, 2, 23. 